ZOOLOGIA 31 (1): 1-7, February, 2014

http://dx.doi.org/10.1590/S1984-46702014000100001

\title{
Behavioral event occurrence differs between behavioral states in Sotalia guianensis (Cetarctiodactyla: Delphinidae) dolphins: a multivariate approach
}

\author{
Rodrigo H. Tardin',2,4, Míriam P. Pinto, ${ }^{2,3}$, Maria Alice S. Alves² \& Sheila M. Simão \\ ${ }^{1}$ Laboratório de Bioacústica e Ecologia de Cetáceos, Departamento de Ciências Ambientais, Instituto de Florestas, \\ Universidade Federal Rural do Rio de Janeiro. Rodovia BR 465 km 7, 23890-000 Seropédica, RJ, Brazil. \\ 2 Departamento de Ecologia, IBRAG, Universidade do Estado do Rio de Janeiro. Rua São Francisco Xavier 524, Maracanã, \\ 20550-011 Rio de Janeiro, RJ, Brazil. \\ ${ }^{3}$ Departamento de Botânica, Ecologia e Zoologia, Centro de Biociências, Universidade Federal do Rio Grande do Norte. \\ Rodovia BR-101, Campus Universitário, Lagoa Nova, 59072-970 Natal, RN, Brasil. \\ ${ }^{4}$ Corresponding author. Email: rhtardin@gmail.com
}

\begin{abstract}
Difficulties in quantifying behavioral events can cause loss of information about cetacean behavior, especially behaviors whose functions are still debated. The lack of knowledge is greater for South American species such as Sotalia guianensis (Van Benédén, 1864). Our objective was to contextualize the behavioral events inside behavioral states using a Permutational Multivariate Analysis of Variance (MANOVA). Three events occurred in the Feeding, SocioSexual and Travelling states (Porpoising, Side flop, Tail out dive), and five events occurred in the Feeding and Travelling states (Back flop, Horizontal jump, Lobtail, Spy-hop, Partial flop ahead). Three events (Belly exposure, Club, and Heading) occurred exclusively in the Socio-sexual state. Partial Back flop and Head flop occurred exclusively in the Feeding state. For the events that occurred in multiple states, we observed that some events occurred more frequently in one of the states $(p<0.001)$, such as Lobtail, Tail out dive horizontal Jump, Partial flop ahead and Side flop. Our multivariate analysis, which separated Socio-sexual behavior from Feeding and Travelling, showed that the abundance of behavioral events differs between states. This differentiation indicates that some events are associated with specific behavioral states. Almost $40 \%$ of the events observed were exclusively performed in one state, which indicates a high specialization for some events. Proper discrimination and contextualization of behavioral events may be efficient tools to better understand dolphin behaviors. Similar studies in other habitats and with other species, will help build a broader scenario to aid our understanding of the functions of dolphin behavioral events.
\end{abstract}

KEY WORDS. Aerial behavior; behavioral analysis; Guiana dolphin; surface behavior.

One of the major problems of cetacean behavioral studies is the clustering of different behaviors into only one category, such as jumps (Lusseau 2006, Azevedo et al. 2009). Altmann (1974) described two classes of behaviors: long duration behaviors in which the most common measure is the duration of this behavior and behavioral events, short duration behaviors in which the most common measure is the occurrence of each event. Under this classification, several events may occur inside a single behavioral state. Although most cetacean behavioral studies investigate behavioral state patterns (SHANE 1990, Geise et al. 1999, Karczmarski et al. 2000, DaURA-Jorge et al. 2007, Nery et al. 2010), behavioral events may also provide important information.

Difficulties associated with the quantification of behavioral events in the wild have resulted in a scarcity of studies in this area and limited information about cetacean behavior (Lusseau 2006, Vaughn et al. 2011). Cetaceans only spend a frac- tion of their time on the surface, and oftentimes the lack of underwater visibility makes full understanding of their behavior difficult. Thus, the investigation of which behavioral events occur in the different behavioral states will provide new know ledge in this area.

This contextualization is better understood for some cetacean species such as the bottlenose dolphin, Tursiops truncatus (Montagu, 1821) (Acevedo-Gutierrez 1999, Lusseau 2006, Miller et al. 2010). However, for "data deficient" species, such as the Guiana dolphin, Sotalia guianensis (Van Benédén, 1864) (IuCN 2013) there are no available data. Although some studies have analyzed behavioral events in S. guianensis's repertoire (e.g., ARAujo et al. 2008, NASCIMENTO et al. 2008), quantification and proper discrimination between states and events is still lacking.

The Guiana dolphin, S. guianensis, is a small delphinid that inhabits estuaries and bays from northern Honduras (CARR \& Bonde 2000) to southern Brazil (SIMÕES-Lopes 1988). 
Our general purpose was to investigate and quantify the behavioral events that occur within behavioral states. Our hypothesis is that some behavioral events are associated to one behavioral state or are more frequent in just one. If this is true, it is possible to clearly define groups of behavioral states in a multivariate analysis from behavioral event occurrences. Our hypothesis derives from findings on related species (e.g., T. truncatus) in which some events are associated to one behavioral state (e.g., LuSSEAu 2006). The investigation of the association between behavioral events and states aids the understanding of the general behavior of $S$. guianensis, since oftentimes only some conspicuous events (such as jumps) can be observed, which provides little information about the behavior of the group.

\section{MATERIAL AND METHODS}

Ilha Grande Bay $\left(23^{\circ} 8^{\prime} 26^{\prime \prime} \mathrm{S}, 44^{\circ} 14^{\prime} 50^{\prime \prime} \mathrm{W}\right)$ is a large estuarine system on the southern coast of Rio de Janeiro, southeastern Brazil (Signorini 1980). Marine habitats of this bay act as transition areas between the land and the sea by receiving organic matter from river drainage and mangrove production (Nogara 2000). The bay receives deep nutrients from the sea derived from the South Atlantic Central Waters - SACW (SignORINI 1980).

Our sampling occurred in the western part of the bay, which includes shallow areas $(<10 \mathrm{~m})$ inhabited by a S. guianensis population (LoDI 2003). Sotalia guianensis inhabits this part of the bay throughout the year, and $63.9 \%$ of the population presents some kind of residency (EspécIE et al. 2010). Groups include up to 18 individuals and may include offspring (TARDIN $e t$ al. 2013a, b). The Ilha Grande Bay population, the largest population of $S$. guianensis, has an estimated 1,311 individuals (CI 95\%: 1,232-1,389). (Mariana de Assis Espécie, pers. comm.)

We used continuous samplings using a digital handycam SONY DCR-TRV $120^{\circledR}$ (ALTMANN 1974) on board a $7.5 \mathrm{~m}$ vessel from May 2007 to March 2010. Two different approaches were used: focal group for behavioral states recording and all-occurrence sampling for behavioral events (MANN 1999). We followed random routes to search for dolphins, which maximized coverage of the sampling area. When a group of dolphins was sighted, we reduced the boat's velocity and filmed the group from a distance of $15 \mathrm{~m}$. A group consisted of individuals within $10 \mathrm{~m}$ from one another, according to the chain rule definition (SMOLKer et al. 1992).

In our study we used ALtmann's (1974) categorization of long duration behaviors, or behavioral states, and short duration behaviors, or events. The behavioral states used were: Feeding, Travelling, and Socio-Sexual. Definitions and group sizes for each behavioral state are given in Table I. In Ilha Grande Bay, all occurrences of Feeding state were performed in groups (TARDIN et al. 2011). Other behavioral states like rest and play are not listed because they were not observed in our study.
We used videoclips as sampling units. Videoclips were restricted to a maximum of 300 seconds, since clips larger than 300 seconds were rare. Clips larger than 300 seconds were divided into several 80 second clips, and two of these were randomly selected. The 80 seconds interval duration was chosen to standardize our dataset since this represents the mean duration of the videoclips.

Every time we spotted a group of dolphins, we recorded following the above cited protocol. We first identified the behavioral state of the group and then analyzed all the behavioral events performed by all individuals inside that group in each videoclip by counting the number of times each event was performed. The slow frame-to-frame analysis of videoclips allowed a proper identification from both states and events. Each performance of a behavioral event was considered as one occurrence.

We observed 12 behavioral events. Seven of these events were also observed by Lusseau (2006), and we thus used his terms to ease comparisons: Horizontal Jump, Lobtail, Side flop, Spy-hop, Tail out dive, Back flop and Head flop. For a description of these events see Lusseau (2006). Belly up and Forward slap definitions were taken from SHANe (1990) and Porpoising from Weirs (2002). Other two events we defined as: Heading, when an individual dolphin hits another with its beak/head; and Club, when a dolphin stands vertically in the water with body partially out of the water and re-enters the water hitting another dolphin.

We constructed an abundance matrix of the different events in each sampling unit (video clip). Then we counted the relative proportion of each event in the different states. We performed a Multi Dimensional Scaling ordination (MDS) using Bray-Curtis dissimilarity index to investigate the cooccurrences of the different events (LEgENDRE \& LEGENDRE 1998). In the MDS plot we used behavioral states as a grouping variable to investigate whether some events or combinations of events were more associated with one or more other states.

We used a one-way non-parametric MANOVA permutation test $(5,000$ permutations, ANDERSON 2001) to test whether the multivariate mean of the abundance of events varied among the three behavioral states using the software R (Package: vegan, OKsanen et al. 2013). This test was chosen because our data did not meet parametric assumptions (Anderson 2001). Posthoc tests were done using separate permutation tests across the pair of groups being compared (ANDERSON 2001).

\section{RESULTS}

We performed 28 boat trips, in which we spent 100.5 hours at the sea and 42.1 hours (41.9\%) directly observing $S$. guianensis. The behavioral state we observed most frequently was Feeding (338.3 minutes, 65.1\%), followed by Travelling (160.5 minutes, $30.9 \%$ ) and Socio-sexual (20.6 minutes, $4 \%$ ). 
Summary statistics for group size related to each behavioral state is presented in Table I. From these hours of observation we created 678 videos. The duration of the 462 videos (68.1\%) in which we did not observe behavioral events was: Feeding: 44.6s \pm 37.1s; and Travelling: $50.1 \mathrm{~s} \pm 42.0 \mathrm{~s}$. The duration of the 216 videos (31.9\%) in which we observed at least one event: Feeding: $88.5 \mathrm{~s} \pm 102.1 \mathrm{~s}$; Travelling: $87.0 \mathrm{~s} \pm 104.4 \mathrm{~s}$; and SocioSexual: $38.7 \mathrm{~s} \pm 31.2 \mathrm{~s}$.Videos with events were the only ones used in the multivariate analyses.

The proportion of each event in the three different behavioral states is shown in Fig. 1. Three events occurred in all three states (Porpoising, Side flop, Tail-out-dive), five of them occurred in two states (Back flop, Horizontal jump, Lobtail, Spy-hop, Partial flop ahead). Three events (Belly exposure, Club, and Heading) occurred exclusively during the Socio-sexual state. Partial back flop and Head flop occurred exclusively during the Feeding state. For the events that occurred in more than one state, we observed that some events occurred more frequently in one of them, such as Lobtail (66\% in Feeding), Tail out dive ( $80 \%$ in Feeding), Horizontal jump (88\% in Feeding), Partial flop ahead (86\% in Feeding) and Side flop (61\% in Feeding) (Table II).

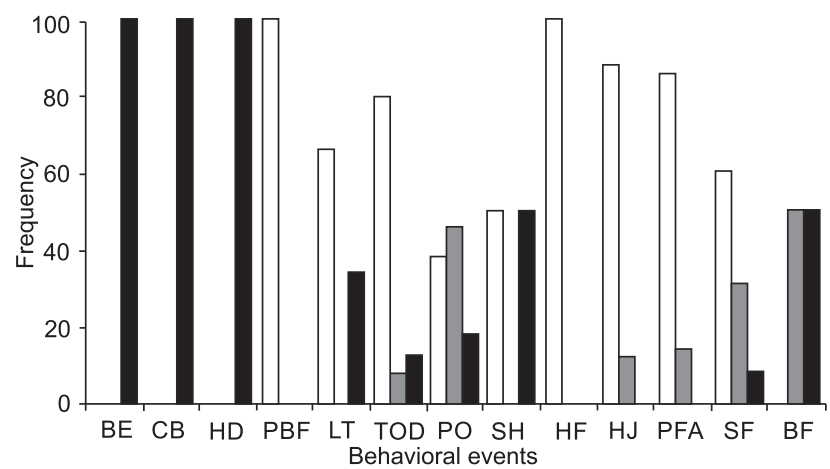

Figure 1. Frequency of occurrence for each event in the three behavioral states. (HJ) Horizontal jump, (PFA) partial flop ahead, (PO) porpoising, (SF) side flop, (PBF) partial back flop, (LT) Lobtail, (TOD) tail out dive, (SH) spy-hopping, (CB) club, (HD) heading, (HF) head flop, (BE) belly exposure, (BF) back flop, ( $\square$ ) feeding,

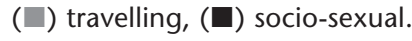

A strong separation between Socio-sexual and the other Feeding and Travelling events was found through MDS ordination, which explained $91.04 \%$ of the variance (Fig. 2). Behavioral events abundance differed among the behavioral states (MANOVA: $\mathrm{F}=17.8$, d.f. $=2, \mathrm{p}<0.01$ ). The post-hoc pairwise comparisons were significant between Feeding and Travelling events $(\mathrm{F}=2.5$, d.f. $=1, \mathrm{p}=0.03)$, Feeding and Socio-sexual ( $\mathrm{F}$ $=28.2$, d.f. $=1, \mathrm{p}<0.01)$ and Travelling and Socio-sexual events $(\mathrm{F}=28.2$, d.f. $=1, \mathrm{p}<0.01)$.

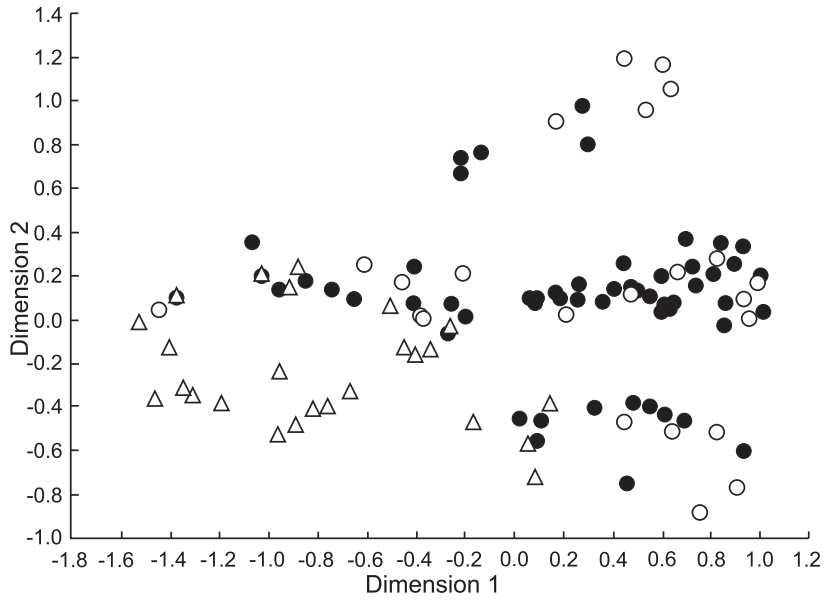

Figure 2. MDS ordination using occurrences of behavioral events grouped by behavioral states. Stress: 0.14 . ( $\bullet$ feeding, $(\bigcirc)$ travelling, (A) socio-sexual.

Table I. Definitions and group size for each behavioral state observed in Guiana dolphins' population in Ilha Grande bay, Rio de Janeiro, Brazil.

\begin{tabular}{|c|c|c|c|}
\hline & Definition & Reference & Group size \\
\hline Feeding & $\begin{array}{l}\text { When individuals did not show } \\
\text { directional movements and dove } \\
\text { frequently in asynchronous } \\
\text { fashion }\end{array}$ & $\begin{array}{l}\text { KARCZMARSKI et } \\
\text { al. }(2000)\end{array}$ & $\begin{array}{l}21.4 \pm 29.2 \\
(3 \text { to } 200)\end{array}$ \\
\hline Travelling & $\begin{array}{l}\text { Directional and persistent } \\
\text { movements }\end{array}$ & $\begin{array}{l}\text { KARCZMARSKI et } \\
\text { al. }(2000)\end{array}$ & $\begin{array}{l}20.9 \pm 29.1 \\
(4 \text { to } 150)\end{array}$ \\
\hline Socializing & $\begin{array}{l}\text { Socio-sexual behavioral states } \\
\text { occurred when individuals } \\
\text { focused on each other, and the } \\
\text { belly-to-belly position was } \\
\text { frequently observed }\end{array}$ & $\begin{array}{l}\text { SLOOTEN } \\
(1994)\end{array}$ & $\begin{array}{l}6.2 \pm 2.8 \\
(2 \text { to } 15)\end{array}$ \\
\hline
\end{tabular}

Table II. Frequency of behavioral events in the different behavioral states of Sotalia guianensis at Ilha Grande Bay, Brazil. In parenthesis, there is the proportion of each event in relation to the total occurrences.

\begin{tabular}{lccc}
\hline Behavioral events & Feeding & Travelling & Socio-sexual \\
\hline Horizontal jump & $337(0.88)$ & $44(0.12)$ & $0(0.0)$ \\
Partial flop ahead & $214(0.86)$ & $34(0.14)$ & 0 \\
Porpoising & $24(0.38)$ & $29(0.46)$ & $10(0.18)$ \\
Side flop & $8(0.61)$ & $4(0.31)$ & $1(0.08)$ \\
Partial back flop & $1(1.0)$ & 0 & 0 \\
Lobtail & $33(0.66)$ & $0(0.0)$ & $17(0.34)$ \\
Tail out dive & $32(0.8)$ & $3(0.075)$ & $5(0.125)$ \\
Spy-hopping & $4(0.5)$ & $0(0.0)$ & $4(0.5)$ \\
Club & 0 & 0 & $3(1.0)$ \\
Heading & 0 & 0 & $9(1.0)$ \\
Head flop & $6(1.0)$ & 0 & 0 \\
Belly exposure & 0 & 0 & $45(1.0)$ \\
Back flop & 0 & $1(0.5)$ & $1(0.5)$ \\
\hline
\end{tabular}




\section{DISCUSSION}

Our data rejected the null hypothesis that some events would co-occur with similar frequencies in some behavioral states. The abundance of behavioral events is clearly different between states, as revealed by our multivariate analysis results, which separated mainly Socio-sexual behavior from Feeding and Traveling. This quantitatively supports the strong association of some events to specific behavioral states. Our proposed analysis tried to exclude the subjectivity of observers while at the same time maintaining flexibility to assess regional adaptations. This is the first study that quantitatively contextualized behavioral events for the lesser known S. guianensis.

Three of these events were performed in the Socio-sexual context. Belly exposure was observed 45 times only during the Socio-sexual state which indicates a strong relationship with this state. In fact, Belly exposure was frequently associated with movements of an individual (presumably males) directing its belly to another individual's belly (presumably females). This movement is considered to indicate courtship, since the genital regions of males and females are located in the posterior part of the belly. However, instead of engaging in sexual intercourse the individual on top turned its belly to the surface and avoided the copulation attempt by placing the genital region out of reach of the male. This may occur when females do not want to copulate with the specific male for many reasons. Interestingly, in one situation that lasted about thirty minutes we could observe twenty individuals copulating in belly-to-belly behavior without any sign of Belly exposure. This situation reported in our study and quantitatively assigned to the Socio-sexual state may be an indication of female active choice of males, a subject that remains unclear for dolphins (WHiteHEAD \& MANN 2000), especially for $S$. guianensis. Another hypothesis that we can draw from our data is that these females may be feeding their calves and therefore are not in an estrous cycle. Most dolphins display a polyestrous cycle, which allows females to copulate several times in a year. Forced copulations may occur during the estrous cycle and females may actively avoid these situations (WHITEHEAD \& MANN 2000) by exposing their belly to the surface, out of the water. Sometimes males force females to enter into an estrous cycle by killing their offspring. When their offspring die, the female may be able to copulate and generate other offspring (WhiteHEAD \& MANN 2000). Although it is rare, an infanticide case was already reported for an adjacent population of $S$. guianensis in Sepetiba Bay in which males were harassing one female, which resulted in the death of her calf (NERY \& Simão 2009). This kind of interaction has also been documented in other dolphins, such as the common bottlenose dolphin in northeast Scotland (PATterson et al. 1998). In order to understand the proximate function of this behavior, the investigation of male rejection frequency by females with and without offspring in the population may unravel interesting questions about female active mate selection in dolphins.
The other two events exclusively performed in the Sociosexual state (Club and Heading) seem to be related to aggression cases since they involve hitting other individuals. These events may be performed by males harassing females for sexual purposes or by females avoiding aggressive bachelor males. Tursiops aduncus (Ehrenberg, 1833) males form alliances to aggressively harass females at Shark Bay (Australia) (ConNor et al. 2001). Aggressive interactions establish dominance hierarchies and can be an important driving force in the regulation of population density and dynamics.

The existence of some events exclusively performed in one state may have some evolutionary benefits. For instance, if some individuals recognize that some events are particularly performed for courtship purposes, the non-verbal communication displayed with the event would be better transmitted and, therefore, a lower energetic cost would be associated when individuals are seeking mates. This might also be true for aggressive interactions. When two or more individuals are displaying specific events that indicate agonistic interactions, nearby individuals that can understand the signs will be able to act, whether escaping or engaging the conflict. For instance, in common bottlenose dolphins aggression is expressed through posture, movement and sound, in which dolphins slam, ram and bites each other (CONNOR et al. 2000). Therefore it is important for the individuals to understand the signals to adopt a better strategy to minimize the energy expenditure and maximize their survival or breeding success. Nevertheless, for future studies, the recognition that some behavioral events are aggressive and context-dependent may help to quantify agonistic interactions in the future and to understand and test hypotheses about aggression in S. guianensis.

Our data suggest that dolphins may use a single behavioral repertoire for different functions. Aerial events may have different implications when used in Feeding, Travelling or Socio-sexual states. In Feeding states, aerial events may facilitate feeding by driving fish towards other dolphins and increasing capture success. Jumps associated with coordinated feeding tactics were documented in an Ilha Grande Bay population of S. guianensis (TARDIN et al. 2011). These jumps may serve as a complementary strategy to herd and increase prey capture. In a T. truncatus population from Isla del Coco (Costa Rica), jumps were used to aid in capturing prey (AcevedoGutierrez 1999). Our data showed that Horizontal Jump, Side Flop and Partial Flop Ahead occurred most frequently in the Feeding state. Jumps in which dolphins entirely leave the water (Horizontal jump and Side flop) may produce the largest percussive effect in the water, which disrupts schools of fish. However, in the Travelling state, leaps may be used to increase swimming speed since friction is lower in the air and turbulence forces are lower (Purcell 1977). The aerial events observed in the Socio-sexual state were Back flops and Side flops. Leaps may have a communicative function as well. These movements may function as visual cues for dolphins to aggregate (NorRIs 
\& DoHL 1980), as a type of communication which would avoid competition between the groups (Lusseau 2006). Knowledge about why dolphins jump in the wild may be important in understanding their behavior. This event is conspicuous and therefore easy to visualize in the wild.

Comprehending the context of conspicuous events may help scientists to more easily understand the nature of dolphins' behavior and therefore provide tools for their conservation. For example, if we understand that some jumps are directly related to the Feeding behavioral state, we can prioritize conservation areas that are used for feeding purposes. This seems to be especially true for the Ilha Grande Bay population since fisheries and tourist activities are continually increasing. The presence of an oil maritime station, two nuclear power plants, and a large shipyard currently threaten the condition of the environmental reserve. Since this area supports the largest documented population of $S$. guianensis, these threats may harm the genetic diversity of this species in a global context.

Tail-out-dive, mostly observed during Feeding, suggests a diving behavior to capture demersal prey such as Porichtys porosissimus (Cuvier, 1829), which is one of the principal prey items of Guiana dolphins in the study area (BERNARDEs et al. 1989). The western part of Ilha Grande Bay has a sandy/muddy bottom with cryptic prey species, and dolphins may have to use echolocalization clicks more often to find prey in this region. Since the study area is shallow, dolphins may forage on the bottom for a longer time, which increases their chances of finding and capturing prey.

Lobtails can also be used as percussive events to drive fish in the Feeding state, the state with which they are most associated. This event was used by T. aduncus in Shark Bay (Australia) to induce an alarm reaction in fish and facilitate their detection (CoNNor et al. 2000). This event was also associated with T. truncatus in shallow seagrass waters in Sarasota Bay (Florida, USA) (WeIss 2006). Although depth was not measured in the present study, the western part of Ilha Grande Bay is also a shallow habitat $(<10 \mathrm{~m})$. In the Socio-sexual state, Lobtails can be used in agonistic interactions, especially male-female ones. Lobtails are used in a non-vocal communicative fashion by Stenella frontalis (Cuvier, 1829) in the Bahamas (Herzing 2000). These actions are used particularly to gain the attention of other dolphins, which will observe the direction that the animal is heading.

Spy-hopping occurred in similar proportions in Feeding and Socio-sexual states. In Feeding, this event could occur as cues to orientation, and dolphins might use it to aggregate to feed (Shane 1990). In socializing, this event could have sexual purposes (SLooten 1994, Lusseau 2006).

The Porpoising event occurred in similar proportions for Travelling and Feeding, with a slightly higher occurrence in the Travelling state. In this context, Porpoising may be used to increase speed to reach a destination. Dolphins hold their dorsal region out of the water, which reduces turbulence forces, and their ventral region in the water, which provides benefits from the lower gravity forces (PurCelL 1977). In the Travelling state this event was performed by all and/or almost all of the individuals of the group and several times by each one. In the Feeding state, Porpoising seems to be shorter and involves fewer individuals, and it might be used to chase prey, especially individually.

The exclusivity of some events and multi-purpose of others can indicate that Guiana dolphins repertoire may be broad and only a subset of these events may be displayed by different population along its distribution. Nevertheless it is important to have in mind that some specific behavioral events can have a pattern to be compared among populations, but exclusivity and sharing of events can be good proxies to understand the diversity of Guiana dolphin behavior. An interesting subject that we also have to consider is that some events could have been more frequent in our study because Guiana dolphins used Ilha Grande bay primary as a feeding place (more than $60 \%$ of groups behavioral budget was feeding). It is possible that other regions that Guiana dolphins use more frequently for other purposes than feeding may present a different subset of events.

The present study creates a methodological framework to analyze Guiana dolphins' behavior in a multidimensional perspective. At the behavioral and ecological aspect, this study is a valuable contribution to investigate $S$. guianensis behavioral diversity and the comparison among different populations may highlight regional differences along its distribution. Moreover, the validation and replication of this framework for other Guiana dolphins' population will allow using behavioral events as an important conservation tool.

\section{ACKNOWLEDGMENTS}

We thank Sergio C. Moreira, Dona Elza, Tico, Gilberto and students of the LBEC for their support. We also thank the solicitude and availability from two anonymous reviewers. Rodrigo H. Tardin is in Programa de Pós-Graduação em Ecologia e Evolução, Departamento de Ecologia, IBRAG, Universidade do Estado do Rio de Janeiro (UERJ). Personnel for this study were partially supported by the Fundação de Amparo à Pesquisa do Estado do Rio de Janeiro (FAPERJ) (R.H.O. Tardin, Grant number E-26/151.047/2007 and Grant number E-26/100.866/ 2011); The Coordenação de Aperfeiçoamento de Pessoal de Nível Superior (CAPES) (R.H.O. Tardin) and Cetacean Society International. M.A.S.Alves received fellowship and research grant associated from CNPq - process 308792/2009-2.

\section{LITERATURE CITED}

Acevedo-Gutierrez, A. 1999. Aerial behavior is not a social facilitator in bottlenose dolphins hunting in small groups. Journal of Mammalogy 80 (3): 768-776. 
Anderson, M.J. 2001. A new method for non-parametric multivariate analysis of variance. Austral Ecology 26: 32-46.

Altmann, J. 1974. Observational study of behavior: sampling methods. Behavior 49 (3-4): 227-267.

Araujo, J.P.; A. Souto; L. Geise \& M.E. Araujo. 2008. The behavior of Sotalia guianensis (Van Benédén) in Pernambuco coastal waters, and a further analysis of its reaction to boat traffic. Revista Brasileira de Zoologia 25 (1): 1-9.

Azevedo, A. F.; T.L. Bisi; M. Van Sluys; P.R. Dorneles \& L. Brito JR. 2009. Comportamento do boto-cinza Sotalia guianensis (Cetacea: Delphinidae): Amostragem, termos e definições. Oecologia Brasiliensis 13 (1): 192-200.

Bernardes, A.T.; A.B. Machado \& A.B. Ryland. 1989. Fauna brasileira ameaçada de extinção. Belo Horizonte, Fundação Biodiversitas.

CARR, T. \& R.K. Bonde. 2000. Tucuxi (Sotalia fluviatilis) occurs in Nicaragua, $800 \mathrm{~km}$ north of its previously known range. Marine Mammal Science 16 (2): 447-452. doi: 10.1111/ j.1748-7692.2000.tb00936.x.

Connor, R.C.; J. Mann; P. Tyack \& H. Whitehead. 2000. The social lives of whales and dolphins, p.1-6. In: J. ManN; R.C. Connor; P. Tyack \& H. Whitehead (Eds). Cetacean Societies: Field studies of dolphins and whales. Chicago, The University of Chicago Press, 433p.

Connor, R.C.; M. Heithaus \& L. Barré. 2001. Complex social structure, alliance stability and mating access in a bottlenose dolphin "supper-alliance". Proceedings of Royal Society B: Biological Sciences 268 (1464): 263-267. doi: 10.1098/ rspb.2000.1357.

Daura-Jorge, F.G.; M.R. Rossi-Santos; L.L. Wedekin \& P.C. SimõesLOPES. 2007. Behavioral patterns and movement intensity of Sotalia guianensis (P.J. Van Benéden) (Cetacea, Deplphinidae) in two different areas in Brazilian coast. Revista Brasileira de Zoologia 24 (2): 265-270.

Espécie, M.A.; R.H.O. Tardin \& S.M. Simão. 2010. Degrees of residence of Guiana dolphins (Sotalia guianensis) in Ilha Grande Bay, south-eastern Brazil: a preliminary assessment. Journal of Marine Biological Association of United Kingdom 90 (8): 1633-1639. doi:10.1017/S0025315410001256.

Geise, L.; N. Gomes \& R. Cerqueira. 1999. Behaviour, habitat use and population size of Sotalia fluviatilis (Gervais, 1853) (Cetacea: Delphinidae) in the Cananéia estuary region, SP, Brazil. Revista Brasileira de Biologia 59 (2): 183-194.

Herzing, D. L. 2000. Acoustics and social behaviour of wild dolphins: implications for a sound society, p. 224-271. In: W.L. Au; A.N. Popper \& R.R. FAY (Eds.). Hearing by Whales and Dolphins. New York, Springer, 487p.

IucN. 2013. Red List of threatened species. Accessed in; 14/06/ 2013

Karczmarski, L.; V.C. Cockcroft \& A. Mclachlan. 2000. Habitat use and preferences of Indo-Pacific humpback dolphins Sousa chinensis in Algoa Bay, South Africa. Marine Mammal Science 16 (1): 65-79. doi: 10.1111/j.1748-7692.2000.tb00904.x.
Legendre, P \& L. Legendre. 1998. Numerical Ecology. Amsterdam, Elsevier, 990p.

Lodi, L. \& B. Hetzel. 1998. Grandes agregações do boto-cinza (Sotalia fluviatilis) na Baía da Ilha Grande, Rio de Janeiro. Bioikos 12 (2): 26-30.

Lusseau, D. 2006. Why do dolphins jump? Interpreting the behavioural repertoire of bottlenose dolphins (Tursiops sp.) in Doubtful Sound, New Zealand. Behavioural Processes 73: 257-265. doi:10.1016/j.beproc.2006.06.006.

MAnN, J. 1999. Behavioral Sampling Methods For Cetaceans: A Review And Critique. Marine Mammal Science 15 (1): 102-122.

Miller, L.J.; M. Solangi \& S.A. Kuczaj. 2010. Seasonal and diurnal patterns of behavior exhibited by Atlantic bottlenose dolphins (Tursiops truncatus) in the Mississippi Sound. Ethology 116 (12): 1127-1137. doi: 10.1111/j.1439-0310.2010.01824.x.

Nascimento, L.F.; P.I.A.P. Medeiros \& M.E. Yamamoto. 2008. Descrição do Comportamento de Superfície do Boto Cinza, Sotalia guianensis, na Praia de Pipa - RN. Psicologia: reflexão e crítica 21 (3): 509-517.

NerY, M.F. \& S.M. Simão. 2009. Sexual coercion and aggression towards a newborn calf of marine tucuxi dolphins (Sotalia guianensis). Marine Mammal Science 25 (2): 450-454. doi: 10.1111/j.1748-7692.2008.00275.x.

NerY, M.F.; S.M. SimÃo \& T. Pereira. 2010. Ecology and behavior of the estuarine dolphin, Sotalia guianensis (Cetacea: Delphinidae) in Sepetiba Bay, South-eastern Brazilian Journal of Ecology and Natural Environment 2 (9): 194-200.

Nogara, P.J. 2000. Caracterização dos ambientes marinhos da Área de Proteção Ambiental de Cairuçu - Município de Paraty - RJ. Technical report, Fundação SOS Mata Atlântica. Rio de Janeiro, 83p.

NoRrIs, K.S. \& T.P. DoHL. 1980. Behavior of the Hawaiian Spinner Dolphin S. longirostris. Fishery Bulletin 77 (4): 821-849.

Oksanen, J.; F.G. Blanchet; R. Kindt; P. Legendre; P.R. Minchin; R.B. O’Hara; G.L. Simpson; P. Solymos; M.H.H. Stevens \& H. Wagner. 2012: vegan: Community Ecology Package. R package version 2.0-3. Available online at: http://CRAN.Rproject.org/package=vegan vegan [Accessed: 14/VI/2013].

Patterson, I.A.P.; R. J. Reid; B. Wilson; K. Grellier; H.M. Ross \& P.M. Thompson. 1999. Evidence for infanticide in bottlenose dolphins: an explanation for violent interactions with harbour porpoises? Proceeding of the Royal Society B: Biological Sciences 265 (1402): 1167-1170.

Purcell, E.M. 1977. Life at low Reynolds number. American Journal of Physics 45: 3-11.

Shane, S.H. 1990. Behavior and ecology of the bottlenose dolphin at Sanibel Island, Florida, p. 245-265. In: S. Leatherwood \& R.R. Reeves (Eds). The Bottlenose Dolphin. San Diego, Academic press.

SignoRINI, S.R. 1980. A study of the circulation in bay of Ilha Grande and bay of Sepetiba. Part I, an assessment to the tidally and wind-driven circulation using a finite element numerical model. Boletim do Instituto Oceanográfico 29 (1): 41-55. 
SIMÕEs-Lopes, P.C. 1988. Ocorrência de uma população de Sotalia fluviatilis Gervais, 1853, (Cetacea: Delphinidae) no limite sul da sua distribuição, Santa Catarina, Brasil. Biotemas 1 (1): 57-62.

SLooten, E. 1994. Behaviour of Hector's dolphin - classifying behaviour by sequence analysis. Journal of Mammalogy 75 (4): 956-964.

Smolker, R.A.; A.F. Richards; R.C. Connor \& J.W. Pepper. 1992. Sex differences in patterns of association among Indian Ocean bottlenose dolphins. Behavior 123 (1-2): 38-69.

TARDin, R.H.O.; M.A. EsPÉCIE; F.T. D’Azeredo; M.F. NerY \& S.M. SIMÃo. 2011. Coordinated feeding tactics of the Guiana dolphin, Sotalia guianensis (Cetacea: Delphinidae), in Ilha Grande Bay, Rio de Janeiro, Brazil. Zoologia 28 (3): 291296. doi: 10.1590/S1984-46702011000300002.

TARDIN, R.; C. GALVÃo; M.A. EsPéCIE \& S.M. Simão. 2013a. Group structure of Guiana dolphins, Sotalia guianensis (Cetacea, Delphinidae) in Ilha Grande Bay, Rio de Janeiro, southeastern Brazil. Latin American Journal of Aquatic Research 41 (2):
313-322. doi: 10.3856/vol41-issue2-fulltext-10.

Tardin, R.H.O.; M.A. Espécie; L. Lodi \& S.M. Simão. 2013 b. Parental care behavior in the Guiana dolphin, Sotalia guianensis (Cetacea: Delphinidae), in Ilha Grande Bay, southeastern Brazil. Zoologia 30 (1): 15-23. doi: 10.1590/ S1984-46702013000100002.

Vaughn, R.L.; E. Muzi; J.L. Richardson \& B. Würsig. 2011. Dolphin bait-balling behaviors in relation to prey ball escape behaviors. Ethology 117 (10): 859-871.

WeIsS, J. 2006. Foraging habitats and associated preferential foraging specializations of bottlenose dolphin (Tursiops truncatus) mother-calf pairs. Aquatic Mammals 32 (1): 9-19.

Whitehead, H. \& J. Mann. 2000. Female reproductive strategies of cetaceans: Life histories and calf care, p. 219-246. In: J. Mann, R.C. Connor, P. Tyack \& H. Whitehead. (Eds). Cetacean Societies: Field studies of dolphins and whales. Chicago, The University of Chicago Press, 433p.

Weirs, D. 2002. Dynamics of Dolphin Porpoising Revisited. Integrative and Comparative Biology 42 (5): 1071-1078.

Submitted: 10.VIII.2013; Accepted: 16.I.2014.

Editorial responsibility: Paulo da Cunha Lana 